\title{
Analysis of Chinese President Xi Jinping's Ecological View: From the Perspective of Transitivity $^{*}$
}

\author{
Hecong Wang \\ School of English, China Three Gorges University, Da Xue Road, Yichang City, Hubei Province, China \\ Xiaoqiong $\mathrm{Hu}$ \\ School of English, China Three Gorges University, Da Xue Road, Yichang City, Hubei Province, China \\ Rui Zhai \\ School of English, China Three Gorges University, Da Xue Road, Yichang City, Hubei Province, China
}

\begin{abstract}
Analysis of ecological discourse can reflect the relationship between language and environmental issues. According to Systemic-Functional Linguistics, language is not only a means of action but also a means of reflection. This study aims to use systemic functional linguistics to analyze Chinese President Xi Jinping's ecological view based on the book Xi Jinping's Comments on Socialism Ecological Construction (Abstract) from the perspective of transitivity, hoping to raise people's ecological consciousness, and lead them to act ecologically and think ecologically in their daily life to protect our precious earth.
\end{abstract}

Index Terms — ecological discourse analysis, transitivity system, Xi Jingpin, ecological consciousness

\section{INTRODUCTION}

With the development of society productivity and the progress of civilization, humanity's cognitive capacity and the ability to transform nature gradually enhanced. Due to the human's unlimited exploitation of the nature, environmental issues have already become the global crisis which seriously affected the survival and progress of humankind. Human beings have to rethink their living and production modes, the relationship between human and nature as well as our views about nature and productivity. In the light of the global serious environmental pollution, deficient of natural resources and great damage to the natural ecosystem, in order to build a moderately prosperous society in all respects and the sustainable development of the world, it is necessary for our human to strengthen the construction of ecological civilization, to respect the law of natural development, to protect the balance of natural ecology, and to integrate the ecological concept into the modernization. Eco-linguistics, which studies the impact of language on the life - sustaining relationships among humans, other organisms and the physical environment, is normative oriented towards preserving relationships which sustain life (Alexander \& Stibbe, 2014). There are two main research approaches, one is Haugen's mode and the other is Halliday's mode. Haugen's mode believes that ecological environment is the basic condition of the language development. Haugen's mode is always known as the social accountability. Halliday emphasizes the significant function of language in settling environmental problems. Nowadays, some linguists start to study Marxist thought in eco-linguistics. "Ecology studies the relationship between man and nature as well as the relationship between man and man. The concern of Marxism thought on the relationship between man and nature is essentially the same as that of Halliday's model of Eco-linguistics" (Liu \& Hui, 2018, p.13). With the prominence of ecological and environmental issues and the transformation of ecological concepts, people gradually realized the important role of Marx and Engels' ecological civilization thoughts in establishing the construction of ecological civilization. As a systematic and scientific theory, the Marxism ecological philosophy has done the all-round research on human and natural relationships as well as tried to build an ecological harmony world. This study aims to use Marxism's natural ecological views as the philosophical foundation and Systemic Functional Linguistics as the linguistic theory basis to analyze Xi Jingpin's ecological views based on the book Xi Jinping's Comments on Socialism Ecological Construction (Abstract), in order to arouse people's ecological consciousness.

\section{DATA Collection}

Since the 18th National Congress of the Communist Party of China, Chinese government has been highlighting the socialism ecological construction. Chinese government has put forward many policies to protect our environment. This

\footnotetext{
* Sponsored by Research Fund for Excellent Dissertation of China Three Gorges University [grant number: 2019SSPY164]
} 
study will take two chapters of Xi Jinping's Comments on Socialism Ecological Construction (Abstract) as the data. Written by CPC Central Research Office, this book contains seven special topics about 80 important excerpts, including Chinese president Xi Jinping's reports, speeches, conversations, indications, comments and congratulatory letters which are related to the ecological construction. The author would study the six and seven subjects of the book. The name of the sixth chapter is that "strengthening citizens' environmental awareness and turning the construction of beautiful China into people's conscious actions". The name of the seventh chapter is that "appealing citizen to actively participate in international cooperation and work together to build a beautiful home on the earth". Chapter six includes 23 excerpts and 3459 Chinese characters (contain marks), which discusses the ecological construction from three angels including citizen, company and government. Chapter seven includes 37 excerpts and 8169 Chinese characters (contain marks). This chapter mainly discusses Chinese international ecological cooperation with other countries such as to fulfill the Paris Agreement. The author uses word segmentation software ITCLAS, corpus processing software Antconc to analyze the data and applies qualitative and quantitative methods to make an analysis of the excerpts, and supplement the methods of inductive and deductive. Furthermore, this study will be based on some basic concepts such as Maxis Ecology Philosophy and use them as the ecological standard to guide people when handling the environmental problems. Moreover, this study will probe ecological view from the angels of citizen, company and the government from Xi Jinping's Comments on Socialism Ecological Construction (Abstract) as well as to investigate the influence of the speech after analyzing its language phenomena.

\section{ANALYTiCAL FrAmeWORK}

This study mainly uses transitivity system to analyze the data. Leading with the Systemic Functional Linguistics, combining related research results made by Halliday, Matthiessen, Fawcett and Martin. Chinese linguists Guowen Huang and Wei He (2017) had complete the English Transitivity System and constructed Chinese Transitivity System .

TABLE I

The ENGLish Transitivity SyStem NeTWORK (GUOWEN HUANG \& Wei HE, 2017, P.29-30)
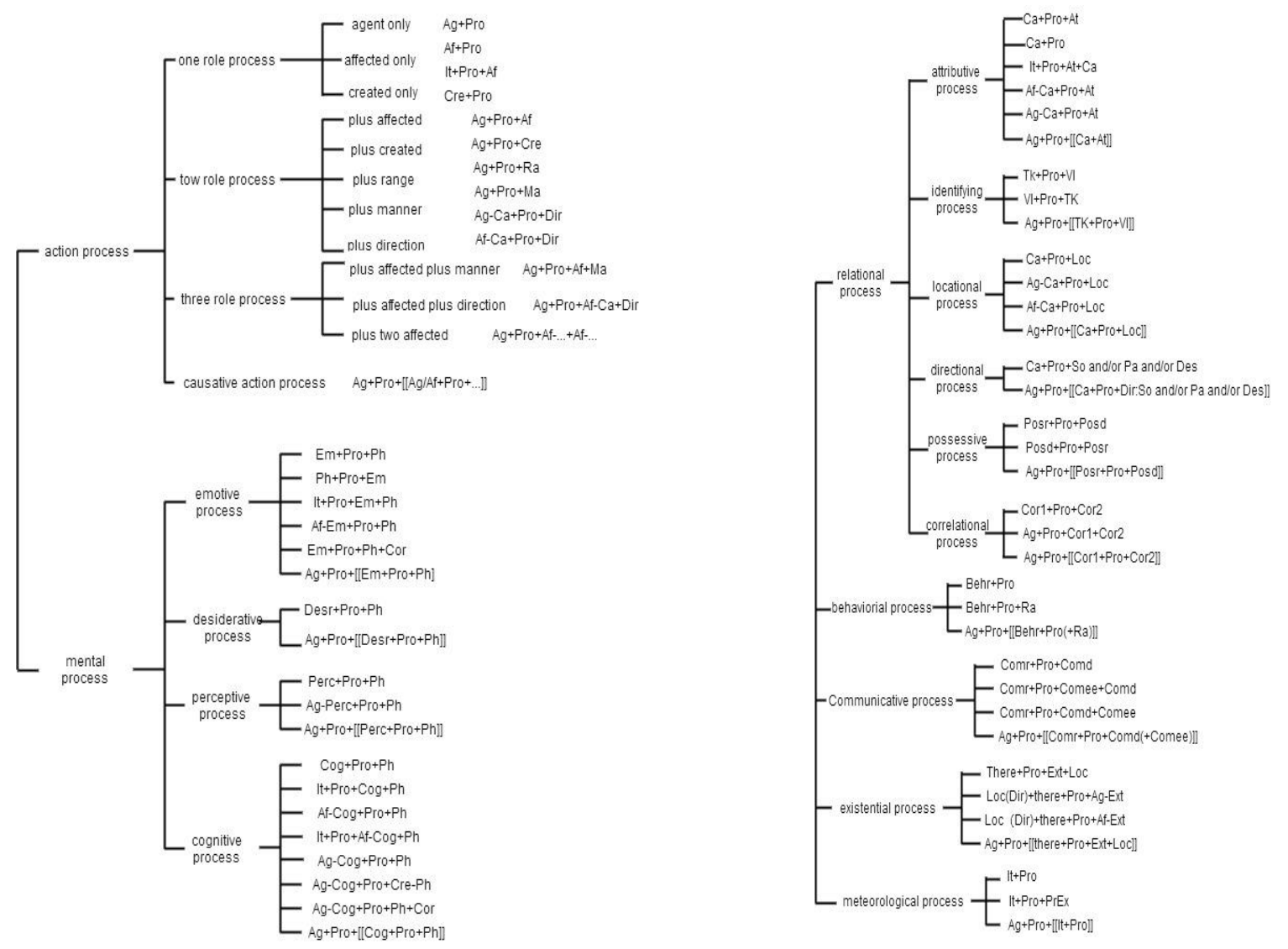

Huang and He have supplemented and further expounded the transitivity system. Similar to Halliday's Transitivity System, they describe human's experiential meaning as seven processes which include action process, mental process, relational process, behavioral process, communicative process, existential process and meteorological process (Huang \& He, 2017, p.20). However, Huang and He (2017) also complete it from three aspects. First, they have changed the name of two processes. In table one, we can find that "material process" is changed to "action process" and "verbal process" is changed to "communicative process". Second, they integrate the relational process into six sub categories. Halliday $(1985,1994 / 2000)$ has mentioned the meteorological process which is between material process and existential 
process. But he had not specifically illustrated the meteorological process. Huang and He (2017) regard the meteorological process as a kind of process moods and describe this process in details. Based on the study of linguists Halliday, Matthiessen, Fawcett, and Martin etc. Huang and He (2017) not only have described the semantic structures of the main process moods including action process, relational process and mental process, but also have clearly described the semantic structures of the sub categories process including behavioral process, communicative process, existential process and meteorological process. From the aspect of analyzing, this theory basically covers all of the language phenomena, and it clearly describes the English and Chinese transitivity semantic structures. The particular semantic structures has improved the accuracy of transitivity system and could reduce the uncertainly factors while analyzing the language phenomenon.

This theory has achieved the combination of causativity and transitivity of English short sentences. There are six kinds of causative process which are causative action process, causative mental process, causative relational process, causative behavioral process, causative communicative process and causative existential process. We have analyzed about 110 different types of articles which written in English and Chinese and acquired rich experience about solving practical problems, which is helpful to enhance and construct English and Chinese transitivity system. (Guowen Huang \& Wei He, 2017, p.33)

The author would also use the Interpersonal Semantic System under the eco-linguistics. Halliday (1994/2000) thinks interpersonal function mainly includes mood and modality system. Then, Martin and White (2005) investigate the vocabulary and divide appraisal system into attitude, engagement and graduation system and create appraisal theory. Ruijie Zhang (2018) believes from the perspective of eco-linguistics, interpersonal system should be developed on mood, modality and appraisal system.

\section{FINDINGS}

\section{A. Word Frequency}

Firstly, the author strictly abides by the rules and sorting techniques of Chinese transitivity system to classifying the book Xi Jinping's Comments on Socialism Ecological Construction (Abstract). After marketing the role and process of all the sentences, the author also picks out the frequency of the words in the whole speech. The author has made three tables. Table one is the frequency of all the words in these two chapters Firstly, the author use Chinese word segmentation system CITCLAS which created by Chinese Academy of Sciences to segment the data, then the author use corpus search tool Antconc to work out the frequency of the words. Table one is about the results of the word frequency. 
TABLE II

WORD FREQUENCY

\begin{tabular}{|c|c|c|c|c|c|}
\hline Number & Frequency & Word & Number & Frequency & Word \\
\hline 1 & 252 & de & 31 & 28 & shi (time) \\
\hline 2 & 131 & nian (year) & 32 & 27 & guo ji (international) \\
\hline 3 & 99 & yue (month) & 33 & 27 & she hui (society) \\
\hline 4 & 97 & ri (day) & 34 & 26 & zhi shu (plant trees) \\
\hline 5 & 78 & zai & 35 & 26 & zi ran (nature) \\
\hline 6 & 69 & yao (need) & 36 & 24 & huan jin (environment) \\
\hline 7 & 66 & $\begin{array}{l}\text { qi hou bian hua (climate } \\
\text { change) }\end{array}$ & 37 & 23 & jiang (will) \\
\hline 8 & 63 & sheng tai (ecology) & 38 & 22 & tui dong (push) \\
\hline 9 & 62 & fa zhan (development) & 39 & 21 & ren min (people) \\
\hline 10 & 59 & shi (is) & 40 & 20 & xie shou (hand in hand) \\
\hline 11 & 57 & dui(to) & 41 & 20 & deng (etc) \\
\hline 12 & 52 & zhong guo (China) & 42 & 19 & er shi (twenty) \\
\hline 13 & 50 & he (and) & 43 & 19 & gong (altogether) \\
\hline 14 & 48 & he zuo (cooperation) & 44 & 19 & guo (nation) \\
\hline 15 & 45 & ying (should) & 45 & 19 & ying gai (should) \\
\hline 16 & 42 & jian she (construction) & 46 & 19 & $\tan$ (carbon) \\
\hline 17 & 40 & $\begin{array}{l}\text { ren min ri bao (Chinese Public } \\
\text { daily news) }\end{array}$ & 47 & 19 & xing dong (action) \\
\hline 18 & 38 & wei (for) & 48 & 19 & zhong yao (important) \\
\hline 19 & 36 & le & 49 & 18 & di (low) \\
\hline 20 & 35 & wo men (us) & 50 & 18 & xie ding (agreement) \\
\hline 21 & 35 & jiang hua (speech) & 51 & 18 & $\begin{array}{l}\text { fa zhan zhong guo jia } \\
\text { (developing country) }\end{array}$ \\
\hline 22 & 34 & quan qiu (global) & 52 & 18 & an quan (safe) \\
\hline 23 & 33 & ba li (Paris) & 53 & 18 & xin (new) \\
\hline 24 & 33 & lv se (green) & 54 & 17 & shi xian (achieve) \\
\hline 25 & 31 & er (two) & 55 & 16 & chi xu (sustainable) \\
\hline 26 & 30 & yi wu (duty) & 56 & 16 & huo dong (activity) \\
\hline 27 & 30 & bao hu (protect) & 57 & 16 & neng yuan (energy) \\
\hline 28 & 29 & wen ming (civilization) & 58 & 15 & chu ban she (press) \\
\hline 29 & 28 & ren lei (human) & 59 & 15 & Jia qiang (strength) \\
\hline 30 & 28 & gong tong (together) & 60 & 15 & guo jia (nation) \\
\hline
\end{tabular}

The author selects the top 60 numbers of the word frequency of the data. In the top ten lists, Chinese auxiliary yao appears 69 times, qi hou bian hua (climate change), sheng tai (ecology), fa zhan (development) appears 66 times, 63 times and 62 times. Words about nation include Zhong guo (China) appears 52 times and guo jia (nation) appears 15 times. The words which mean work together include he zuo (cooperation), gong tong (together), xie shou (hand in hand), gong (altogether) appears 48 times, 28 times, 19 times, 17 times. The words which are relate to nature includes $l v$ se (green), zhi shu (plant trees), zi ran (nature), huan jin (environment), chi xu (sustainable) appears 33 times, 26 times, 26 times, 24 times, 16 times. And the words about people include ren lei (huamn), ren min (people) appears 28 times and 21 times.

\section{B. Participant Role}

According to Chinese linguists Wei He and Rong Wei (2017, p.601), the author divides the participant of the data into four kinds, which includes living, non-living, physical non-living and social non-living. Living could be divided into individual one such as personal pronoun, status word and name. Group human body is like people; non-human livings could be divided into flower species and plant species. While physical non-livings include three parts, which are mountain, landform and climate. Finally, social non-livings include things related to social factors such as country, economy, civilization.

TABLE III

PARTICIPANT ROLE IN THE DATA

\begin{tabular}{|c|c|c|c|}
\hline \multirow{2}{*}{ Living:134 } & \multirow{2}{*}{ Human being:69 } & Individual & 15 \\
\cline { 2 - 3 } & & Group & 84 \\
\cline { 2 - 4 } & \multirow{2}{*}{ Non-human being:35 } & animal & 27 \\
\cline { 3 - 4 } & & plant & Physical non-living: 40 \\
\cline { 2 - 3 } & \multicolumn{3}{|c|}{ Social non-living: 300 } \\
\hline \multirow{2}{*}{ Non-living:340 }
\end{tabular}

From the table, we find that the total number of participant is 474, while livings have 134 and non-livings have 340 . For the livings, the number of human being's participant is more than the non-human being. And for the non-livings, the number of social non-living is more than physical non-living.

C. Process and Proportion 
Based on Chinese Transitivity System, the author has classified the data into seven processes. And count the numbers by using the corpus search tool Antconc.

TABLE IV

PROCESS AND PROPORTION OF THE DATA

\begin{tabular}{|c|c|}
\hline Process & Proportion \\
\hline Action Process: 448 & $71.68 \%$ \\
\hline Relational Process: 118 & $18.88 \%$ \\
\hline Mental Process: 21 & $3.36 \%$ \\
\hline Behavioral Process: 0 & 0 \\
\hline Communicative Process: 14 & $2.24 \%$ \\
\hline Existential Process: 24 & $3.84 \%$ \\
\hline Meteorological Process: 0 & 0 \\
\hline Total number: 625 & $100 \%$ \\
\hline
\end{tabular}

From table 4 , the total number of the process is 625 . It is very obvious that the action process account for most of them is about $71.68 \%$. Relational process covers $18.88 \%$. Next one is existential process which covers $3.84 \%$. And mental process, communicative process is $3.36 \%$ and $3.84 \%$ in the two chapter, while behavioral process and meteorological process have not appeared in the passage.

\section{DISCUSSION}

After analyzing the speech from Chinese Transitivity System, the author would discuss the speech from three dimensions.

\section{A. Multiple Uses of Causative Word and Auxiliary}

After using corpus research tool Antconc to analyze, the author finds that Xi Jinping's speech always use causative word and auxiliary. The causative word includes Chinese ba, shi, rang, wei and Chinese auxiliary yao.

TABLE V

CHINESE CAUSATIVE WORD AND AUXILIARY FREQUENCY

\begin{tabular}{|c|c|}
\hline Causative Word & Auxiliary \\
\hline Ba: 9 & Yao:69 \\
\hline Shi:7 & \\
\hline Rang:8 & \\
\hline Wei:25 & Total:69 \\
\hline Total: 49 & \\
\hline
\end{tabular}

From table 5, we can find the frequency. Based on the modality system (Ruijie Zhang, 2018, p.103), the level of the modality and the semantic meaning have a close connection with each other. When we analyze the modality of the sentence, linguist should also consider the ecological meaning to estimate the semantic values of the passage.

TABLE VI

ECOLOGICAL MODALITY SYSTEM (ZHANG, 2018, P.104)

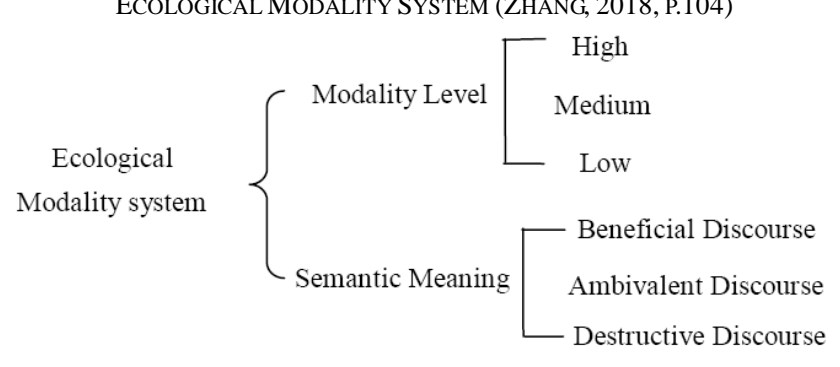

Chinese linguist Wei He (2013) told that Chinese auxiliary yao could be the meaning of permission for the word which follows yao. It means that the word yao supplement the author's attitude towards to the following actions. In English, the words must, can are often used to explain the author's attitude. Considering that, the modality level of Chinese word yao is in high modality level. Lei Wang (2018) concluded that Comparing with the ordinary sentence, sentences with the causative word $b a$ are more subjective and the attitude is much stronger. Sentences with ba could be seen as one kind of special resource which emphasizes the high level of attitude. Jinfeng Li (2017) said that, when it comes to command and permission, Chinese word rang is in medium level and full of strong subjective attitude. The Causative word shi could be the degree modifier (Jinyuan Zhang, 2015, p.22). The degree modifier means to modify the modality of the core words. And causative word shi could make the level of the attitude much higher.

The main theme of these two chapter is appealing for the citizen, company, and government to work together to protect our environment. The theme of chapter six is about to strength the ecological consciousness of people, and to transfer thoughts into practical action. According to Maxis ecological philosophy, human is a part of the nature and 
nature is a part of human's body. As a kind of creature, human's consciousness, life, and activity both originate from nature. According to Max and Engels, human's living and development cannot depart nature, and we must respect and protect nature in a harmonious way (Jin Liu, 2011, p.39). It means that without nature, human cannot survive in the earth. Chapter seven is to appeal for every country to be concerned about the nature. Just as Xi Jinping (2013, p.23) said: "nature is full of happiness and beauty, and protecting nature should be a habit and responsibility." We can find that $X i$ Jinping's Comments on Socialism Ecological Construction (Abstract) is a beneficial discourse. It not only calls upon the citizen of China but also people all over the world to protect nature. And the book also has used many causative words and auxiliaries which are in high modality showing the strong resolution to carry on the great career. Analyzed from the modality level and the semantic meaning of the passage, this passage conforms to the ecological views of the Maxis. It has great influence and ability to broadcast the ecological conscious to the people around the world and lead us to protect our nature.

\section{B. Eco-oriented Participant}

Chinese linguists Huang Guowen and Chen Yang (2018) finds that there is a series of ecological expectation level towards participant. We can see this from table six.

TABLE VII

THE Chain OF PARTICIPANT EXPECTATION LEVEL (WENJUAN ZHOU, 2018, P.528)

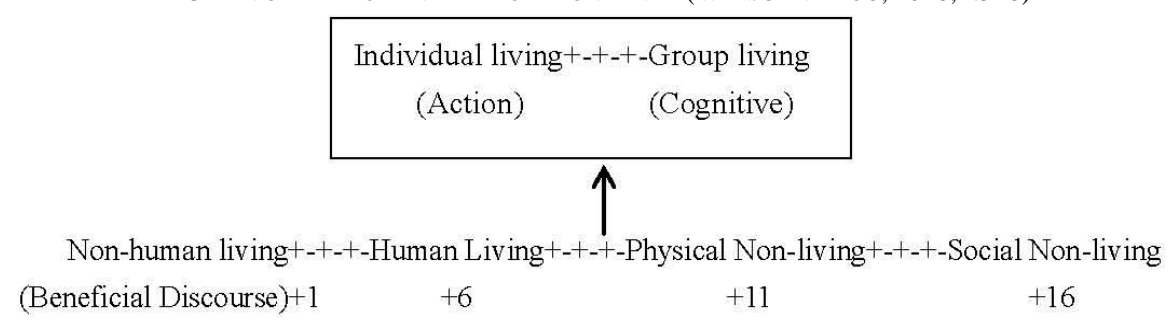

Based on the Marxism Ecological Philosophy, the data is a beneficial discourse. Zhou (2018) predicts the beginning of the chain is 1 and uses the number 5 as one level. Non-human living is in the first level, the expectation of human living is in the second. Physical non-human living is in third level and the social non-living is the top level. As for the individual living, people expect them to take practical action. And for the group living, people expect them to have ecological consciousness.

According to the data of the participant, in these two chapters non-human livings appear 35 times such as trees, wild animals. Human livings appear 69 times such as teenager and human being. While physical non-Livings appears 40 times such as river, sky and social non-livings which appears 300 times such as ecological civilization. In the process of Marxism in China, Chinese government has put out the "People Oriented" policy. It means to uphold the views of human and take the responsibility to protect the environment by insisting sustainable development mode. On the one hand, these words remind people to love the plants and animals, on the other hand, human beings live in a sustainable way. As a beneficial discourse, these languages are in line with the features of Chinese language contexts.

\section{Eco-oriented Process}

Natural production power means the productivity which involves with practice. Human being's basic productivity mood is practice (Xiaoxia $\mathrm{Du}, 2014$, p.35). In the process of practice, human and nature could become one harmony unit. Through practice, the nature not only could sacrifice itself but the human beings can use their advanced technology and sustainable production styles to complete and mend nature.

We can see that the number of total action processes are 448 times, accounting for $71.68 \%$. The view of practice is the theory principle and natural productivity consciousness of Marxism. Numbers of action processes stimulate the great significant of practice. The key verb of the action process could be divide into 4 parts, including action oriented such as bao hu (protect), can yu (join), leading oriented such as chang yi (propose), willing oriented such as xie shou (hand in hand), rong he (combine), developing oriented such as jian she (construct), tui dong (push). From these words, we can find the clear ecological protection views and positive ecological conscious. The passage also largely uses relational process, about 118 times and account for 18.88\%. Marxism ecological views believe that the production of human's society is the combination of nature relationship and social relationship. There are two main relationships in the world, one is the relationship between people, and the other is the relationship between nature and society. The two relationships connect with each other and could not be taken apart. The relational process highlights the relation between nature and human beings and the future of the world. Such as the sentence " $f a$ zhan lin ye (Plant trees) [Tk] is [Pro] quan mian jian cheng xiao kang she hui de zhong yao nei rong (important contents to build a moderately prosperous society in all aspects) [VI] (relational process)"which explicitly shows that the important relationship between nature and our society. Mental process sentences such as "ai (love) [Pro] $l v$ (green) [Ph] (mental process)" and "([Desr] $)$ xi wang (hope) [Pro]" which deliver kind of great expectation towards the future. Communicative process sentence such as "([Comr]) zan shang (praise) [Pro] fa fang zuo wei dong dao zhu fu chu de ju da nu li (the great efforts that made by the meeting host French) [Comd] (communicative process)" which make the speech more dynamic. There 
are also existential process such as "ge di huan bao tou ru (the investment of ecological protection in each city) [Ag] dou zai (both are) [Pro] kuai su zeng zhang (developing in a fast way) [Ext] (existential process)" which means Chinese ecological construction is on its way.

From the above analysis, Xi's ecological views is full of resolution and sincerity to call upon every citizen to care about our environment and to live in a sustainable way and work together to handle the ecological crisis hand in hand.

\section{CONCLUSION}

Based on Chinese Transitivity System (Huang \& He, 2017), Ecological Interpersonal System (Zhang, 2018) theory and Marxism Ecological Philosophy, the author analyzes Xi Jinping's ecological views through two chapters of the book Xi Jinping's Comments on Socialism Ecological Construction (Abstract) from three dimensions. The author analyzes the data by using the word segmentation software ITCLAS, corpus processing software Antconc which make the analyzing more scientific and precise. We find that Xi's speech about ecological construction is persuasive and visionary. With rich connotation and profound thought, Xi Jinping's ecological views are of great guiding significance for the environmental protection. Human beings have the right to pursue better life, however, we also should concern the living of nature. As nature has its own way of living and its own way of running (Ruijie Zhang, 2018, p.33), like Chinese linguist Guowen Huang (2016) said that we should be an ecological man who is full of ecological consciousness rather than ordinary homo economics who grabs what he can for himself.

\section{REFERENCES}

[1] Alexander \& Stibbe. (2014). From the Analysis of Ecological Discourse to the Ecological Analysis of Discourse. Language Sciences, 41(part A), 104-110.

[2] Baojun Xie. (2001). The Eco-philosophy of Marx's Viewpoint towards Nature and Modern Meaning. Hei Longjiang University.

[3] Guowen Huang. (2016). Ecological Orientation of Foreign Language Teaching and Studying. Chinese Foreign Language, 5: 10-13.

[4] Guowen Huang \& Yang Chen. (2018). Indeterminacy in the Classification of Ecological Discourse types. Journal of Beijing International Studies University, 1: 3-14.

[5] Guowen Huang \& Wei He (2017). Functional Semantic Analysis of Chinese. Beijing: Foreign Language and Research Press.

[6] Halliday, M. A. K. (1985). An Introduction to Functional Grammar ( $1^{\text {nd }}$ ed.). London: Arnold.

[7] Halliday, M. A. K. (1994/2000). An Introduction to Functional Grammar (2 ${ }^{\text {nd }}$ ed.). London: Arnold/Beijing: Foreign Language Teaching and Research Press.

[8] Jinfeng Li. (2017). The Emotional Tendency and Construction of Chinese Rang. Modern Chinese, 17: 84-89.

[9] Jin Liu. (2011). Systematic Analysis and Research on Construction of China Ecological Civilization. Party School of the Central Committee of CPC, 39.

[10] Jinyuan Zhang. (2013). A Study of the "Shi"-Causative Construction in Modern Mandarin Chinese: A Cardiff Grammar Perspective. Contemporary Foreign Languages Studies, 5: 22-27.

[11] Litao He. (2018). Study on the Construction of Ecological Civilization in China from the Visual Angle of Marxist Naturalism. Chongqing Normal University.

[12] Lei Wang. (2018). Appraisal Function of Chinese Sentence Ba Constructions. Journal of PLA University of Foreign Languages, 2: 92-94.

[13] Martin, R. \& P. White. (2005). Language of Evaluation: Appraisal in English. London: Palgrave Macmillan.

[14] Party Literature Research Center of CPC Central Committee. (2017). Xi Jinping's Comments on Socialism Ecological Construction. Beijing: Central Party Literature Publisher.

[15] Ruijie Zhang. (2018). A Framework for Eco-oriented Discourse Analysis from the Perspective of Systemic Functional Linguistics. University of Science and Technology Beijing, 33.

[16] Ruijie Zhang \& Wei He. (2018). Interpersonal Meaning System Viewed from an Eco linguistic Perspective. Foreign Language and There Teaching, 2: 101-103.

[17] Wenjuan Zhou. (2018). An Ecological Analysis of Chinese Public Signs on Environmental Protection. Foreign Language and Literature Studies, 5: 522-528

[18] Wei He \& Xue Hua \& Jinyuan Zhang. (2013). The Functional Syntax Study of Chinese Typical Auxiliary yao. Shandong Foreign Language Teaching Journal, 3: 35-40.

[19] Wei He \& Rong Wei. (2007). An Analytical Framework of Transitivity for International Ecological Discourse. Modern Foreign Languages (Bimonthly), 5:601-609.

[20] Wei He \& Rong Wei. (2016). Review of Transitivity Studies within Systemic Functional Linguistics. Journal of University of Science and Technology Beijing, 1:14-17.

[21] Xiaoxia Du. (2014). Marx and Engels' Ecological View of Nature and It's Development in Contemporary China, North eastern University, 35.

[22] Yan Liu \& Hui Yu. (2018). Marxism Thought in the Research of Halliday Eco-linguistics Mood. Journal of University of Science and Technology Beijing, 6:13-18.

[23] Yan Wang. (2011). Research on the Ecological View of Marxism. Nanjing University of Aeronautics and Astronautics. 


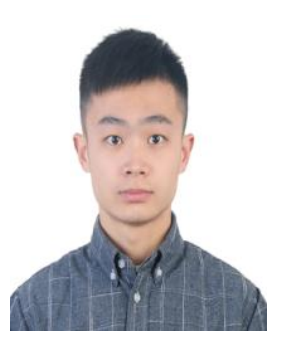

Hecong Wang (Corresponding Author) was born in Shiyan, Hubei Province, China in 1995. He is studying master degree in China Three Gorges University, Yichang, Hubei Province, China.

His currently studying field is Ecolinguistics. His tutor is Professor Hu Xiaoqiong in China Three Gorges University, Yichang, Hubei Province, China.

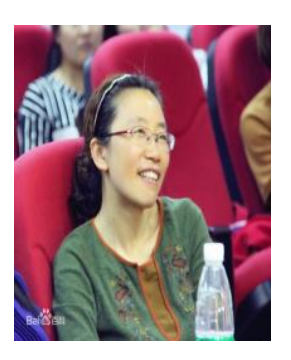

Xiaoqiong Hu wa born in Yichang, China. She received her master degree in linguistics from Guangzhou University of Foreign Language, China in 1995.

She is currently a professor in School of Foreign Languages, China Three Gorges University, in Hubei Province, China. Her research is Second Language Acquisition and World English.

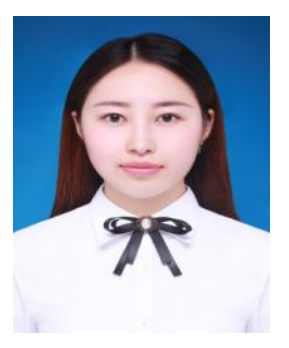

Rui Zhai is a graduate student in School of Foreign Languages, China Three Gorges University, in Hubei Province, China.

Her tutor is Liu Jingxia, who is a professor in English Department, School of Foreign Languages, China Three Gorges University, in Hubei Province, China. She is interested in Discourse Studies and the World English. 